\title{
O DISCURSO DA MEDICINA E DA REZA NA (RE) CONSTRUÇÃO DE IDENTIDADES
}

(The discourse of the medical and of the faith-heal in the (re) construction of identity)

\author{
Sandra Helena Dias de Melo ${ }^{1}$ \\ Jarbas de Goes Nunes ${ }^{2}$ \\ (Universidade Federal Rural de Pernambuco- UFRPE)
}

\begin{abstract}
This paper aims at discussing the identity (re) construction of agents involved in the net of cares in a city located in Pernambuco arid midlands. Assuming that identity is not something found in natura and that language is the source of (re)construction of identity forms (Rajagopalan, 2002), it was observed how discursive practices shape subjects involved in healthcare. Interviews with physicians and faith-healers have made it possible to perceive how discourse about the self and the others help building performatively these subjects' identity. As a result, evidence was shown of preponderance of a discourse based on the negation of the other: on the one side, disqualification of faith-healers' discourse, by physicians, and on the other side limitations of medical knowledge pointed out by faith-healers before the mysteries of the Sacredness.
\end{abstract}

Key words: identity, representational policy, health popular practices

\section{RESUMO}

Este trabalho buscou discutir a (re) construção da identidade dos agentes envolvidos com a rede de cuidados de uma cidade do sertão pernambucano. Partindo do pressuposto de que a identidade não é encontrada in natura e que a linguagem é fonte de (re)construção de formas identitárias (Rajagopalan, 2002), observou-se como as práticas discursivas delineiam os sujeitos envolvidos em rede de cuidados. A partir de entrevistas realizadas

1. Professora Adjunta do Departamento de Letras e Ciências Humanas da Universidade Federal Rural de Pernambuco (DLCH/UFRPE)

2. Sanitarista e Mestrando do Programa Integrado de Pós-Graduação em Saúde Coletiva da Universidade Federal de Pernambuco (PIPASC/UFPE). 
com médicos e rezadores, foi possível perceber como o discurso sobre si e sobre o outro constrói performativamente a identidade desses sujeitos. Como resultado, foi constatado um predomínio de discurso de negação do outro: de um lado, o médico traz uma desqualificação do discurso do rezador, do outro, o rezador aponta os limites do saber médico diante do mistério do sagrado.

Palavras-chave: identidade, poder, política de representação, práticas populares de saúde

\section{Introdução}

Afirmar que a identidade não é algo in natura é reconhecer a sua construção performativa: é, assumi-la, por um lado, como um vira-ser, isto é, em processo constante, e, por outro, reconhecê-la como um efeito do discurso. Reivindicar o conceito do que seja identidade, desse modo, seria também ter que reconhecer estratégias que são promovidas discursivamente para o estabelecimento de uma identidade dos sujeitos que se constroem e se reconstroem pela linguagem a partir da reivindicação de seu eu e do seu outro.

Mas o que se quer dizer com identidade reivindicada? Partindo do pressuposto de que a nomeação é um ato performativo e de que a construção da identidade são atos também políticos (Rajagopalan, 2002), fundamentamos nossa reflexão sobre o discurso da medicina e da reza como um modo de constituição política dos sujeitos para sua identificação ou desidentificação. Nomear, oriunda da palavra latina nominatione (ato ou efeito de nomear), parece ser uma atividade adâmica que serve para identificar algo/alguém. Esta não é exercida, em geral, por qualquer um, já que nem todos são vistos como possíveis autoridades para dar nome às coisas (Platão, Crátilo). Apesar disso, seria no mínimo imprudente não observar que, mesmo os objetos ou seres já nomeados, todos os dias nascem e morrem, porque conceitos são modificados. Daí a necessidade de uma reivindicação constante para certas identidades.

Num mundo descritível e discreto, os nomes (e em muitos casos os números, para não esquecermos que de substantivos passamos a al- 
garismos) servem como índices de identificação. Para isso, é necessária a dicotomia arrumada de alguns conceitos, o que é possível apenas pela dissolução da semântica num mundo de sinais (Horkheimer, 1975; Benhabib, 1996). A perda da multiplicidade de um ser é o efeito do conceito que desencanta o símbolo mágico e minimiza a semântica, ao reduzir a língua a um sistema de sinais que apaga a complexidade das coisas de tal sorte que reduz "a afinidade múltipla do ser à relação entre o sujeito doador de sentido e o objeto de sentido" (Benhabib, 1996: 82).

A explicação para esse ato é a necessidade da estatização dos entes. $\mathrm{O}$ asseio feito nos conflitos existentes se impõe com ou sem a presença de dicionários ou legisladores dos nomes: "mesmo sem a pressão da legislação e dos dicionários, os nossos vocabulários tendem à uniformidade" (Ryle, 1975a: 51). A apresentação de um língua adequada para filtrar os conceitos e as identidades, visa à uniformidade, e visa, sobretudo, à ocultação do caráter avaliativo e político do ato de designação. À medida que um nome identifica algo, ele também predica este sujeito no mundo do discurso, classificando-o.

Por sua vez, a classificação é, em geral, entendida como se fosse uma atividade neutra: professor $\mathrm{X}$ aluno; pais $\mathrm{X}$ filhos; médicos $\mathrm{X}$ não-médicos (ou leigos em medicina). Nessa classificação, o primeiro membro sempre é visto como uma autoridade: um orientador, um chefe, um especialista, e o segundo, como o oposto daquele. Essa conclusão apresenta-se como natural, negando-se a multiplicidade das interpretações possíveis. A classificação feita pela linguagem passa a ser encarada como uma estrutura informativa: constata-se algo. Essa linguagem informativa ou a crença nela oculta o jogo de poder existente nas garantias das identidades em detrimento da multiplicidade dos sentidos possíveis.

Mas a designação e a classificação não são consequências de uma discretização natural, ao contrário, configuram-se como um ato, por carregarem consigo valores e avaliações. Se, para Austin (1990), descrever é nada mais nada menos que performar, isto é, um enunciado não tem como um único fim a realidade, então é preciso, pelo menos, suspender a constatação como o único fim da linguagem: as matérias deixam de ser uma coisa e passam a ser um evento. Essa 
relativização provocada pelo discurso ininterrupto humano evidencia o trabalho realizado pela linguagem - a relação entre linguagem e mundo informado não é uma apresentação, mas uma representação.

A linguagem é, pois, performativa, porque serve como instrumento para a reivindicação de certas identidades em oposição a outras, já que nos constituímos no discurso (Butler, 1997); e, como a própria forma de representar as identidades, a linguagem assegura a fixidez àquilo que é representado por ela. $\mathrm{E}$ isso não é feito de modo imparcial, ao contrário, a linguagem representando o mundo, os acontecimentos, assume um efeito de verdade (Foucault, 2004a) podendo apagar os conflitos e garantir a autonomia não apenas de alguns entes: objetos, pessoas, mas também do poder e da autoridade delegada a alguns.

Dizer que a linguagem é performativa e não informativa, que o uso da língua e a constituição das identidades é um ato político, é observar que o discurso, aqui entendido como ininterrupto no tempo e no espaço - por isso, histórico e social - sobre identidades, é fruto do processo de nomeação e renomeação, uma vez que é resultante de uma classificação que tenta descrever um ente qualquer, não apenas criando-o como entidade, mas garantindo-lhes direito ou deveres a partir de sua denominação. Neste sentido, para refletir sobre a relação criada entre linguagem e identidade, a partir da construção dos sujeitos envolvidos no discurso da medicina e da reza, recorremos aos estudos da Análise Crítica do Discurso feitos por Fairclough (2001), para quem o discurso é organizado por práticas associadas aos "processos de produção, distribuição e consumo textual" (Fairclough, 2001: 106).

Nessa visada, compreende-se discurso não como o curso de formações discursivas homogêneas, fechadas e estruturantes. Para deixar mais clara a filiação deste trabalho ao estudo da heterogeneidade da ordem do discurso, utiliza-se o conceito de prática discursiva em vez de formação discursiva, que, por vezes, mantém um postulado da homogeneidade dos discursos ${ }^{3}$. Assim, objetiva-se identificar as

3. Para Foucault, formação discursiva diz respeito a um conjunto de regras anônimas e históricas, determinadas num dado espaço e num dado tempo em áreas diversas: social, econômica, linguística, pelas condições enunciativas. 
práticas discursivas que dão identidade aos agentes envolvidos com a rede de cuidados do sertão pernambucano.

\section{O Poder e as Práticas Discursivas: a medicina e a reza}

Para Foucault (2004a), o poder não existe na forma de "coisa": ninguém o possui como uma propriedade. $\mathrm{O}$ poder não se dá, não se troca, nem se retoma, pois ele não existe, o que existe, de fato, são práticas e relações de poder. Em outras palavras, o poder é exercido; ele só existe de forma dinâmica, em ato. Manifesta-se de diversas formas, nos diversos níveis da sociedade, realizando um controle minucioso e detalhado dos sujeitos, seja nas atitudes, nos gestos e comportamentos ou nos hábitos e discursos.

O poder pode se revelar não só pelo discurso da ordem, da obrigatoriedade, mas pela distribuição de práticas discursivas que disseminam a desigualdade do "capital social".Para Pierre Bourdieu (1983), o poder surge da distribuição desigual deste "capital" nos diferentes níveis da sociedade. $\mathrm{O}$ "capital social" não é equivalente a capital econômico, mas, sim, a "coisas" como cargo, beleza, dinheiro, títulos, automóvel de luxo, talento, boa oratória etc. - a tudo aquilo que denota poder no universo simbólico cultural de cada sociedade. Nesse sentido, capital social são bens simbólicos que tornam possíveis homens subjugarem outros homens (Bourdieu, op.cit.). A "competência" de proferir enunciados confere poder a alguns usuários da língua, o poder-dizer. A constituição da identidade pelas práticas discursivas que identificam algo e que circulam pela sociedade a partir da designação de um ente e de sua identificação no mundo se faz pela linguagem. Da mesma forma, o êxito do ato de fala dependerá da autoridade que este sujeito assume para proferi-lo. Desse modo alguns sujeitos se apresentam como autoridade do dizer, porque são considerados representantes do que defendem. Assim, são as autoridades da cura, os representantes da medicina e da reza, embora não haja trânsito livre de um desses agentes no domínio discursivo do outro. 
Para entendermos melhor as relações de poder, devemos sempre estar cientes da relação íntima que o poder mantém com o saber e com o dizer, e como essa relação implica na produção e reprodução de verdades. Essas formas de poder, que funcionam e se efetivam na "infraestrutura", dão lugar à relação de conhecimento sujeito-objeto-sociedade com o nome de saber: ter conhecimento, autoridade sobre determinado assunto, poder. Assim, o exercício do poder cria perpetuamente saber e, inversamente, o saber acarreta efeitos de poder e de verdade (Foucault, 2004a).

"Quem detém a verdade?" Poderíamos perguntar: aquele que sabe e que consequentemente possui o direito de exercer o poder?Aquele que tem voz e pode falar de? Seja efeito de verdade seja a própria verdade, já que vivida, a busca por um saber ou uma verdade universal, que sempre permeia os discursos de poder-saber e do poder-dizer, nas instituições, não é uma forma de apreensão de uma realidade pura, mas faz parte das várias estratégias de imposição dos saberes dominantes e de exclusão dos saberes populares marginalizados. Tal reflexão permite-nos afirmar que, neste contexto de cala boca, agiram a ciência, nas raízes do positivismo, a medicina pós-industrial do ocidente e o direito penal, por colocarem a universalidade de seus saberes atrelada ao regime da prova científica, fornecendo uma condição de "pureza" ao saber, produzindo um discurso de uma verdade incontestável. Esses mecanismos desautorizaram o poder-saber e o poder dizer dos grupos vistos como leigos, por desconsiderar os saberes efetivos desses.

Existe um sistema de poder gerado pelo discurso dominante de verdade, que barra, proíbe ou invalida os saberes populares. Este poder sobre a sociedade e os indivíduos não se dá apenas pela consciência ou pela ideologia, através da persuasão, convencimento ou alienação, mas antes começa pelo corpo dos sujeitos. Ainda de acordo com Foucault (2004a: 80), foi "no biológico, no somático, no corporal que, antes de tudo, investiu a sociedade capitalista. O corpo é uma realidade bio-política. A medicina é uma estratégia bio-politíca”. Nada é mais concreto na vida das pessoas do que o corpo.

Embora o ato de fala não possa ser reduzido ao significado da frase nem a intenção do falante, e também não haja motivos para 
apresentá-lo como um ato controlado completamente por mecanismos de poder, o corpo é cuidado/curado pelo ato de fala - se não necessariamente cuidado, a promessa da cura é proferida (cf. Felman, 2003; Foucault, 2004b). Mesmo que o poder-dizer esteja associado ao poder-saber: na nossa sociedade quem pode falar é aquele que sabe, o poder-saber e dizer oficial, o das práticas discursivas hegemônicas, como o da medicina, não consegue calar o poder-saber e dizer de sujeitos como as/os rezadeiras/rezadores. Em outras palavras, a história do poder-dizer e do poder-saber, derivadas de estratégias do poder hegemônico, não impede que outras identidades coexistam e reivindiquem para si também a função de cuidadores da saúde. ${ }^{4}$

Não foi com as práticas da clínica individual que a medicina ganhou relevância na produção capitalista, mas foi no enfoque coletivo e no desenvolvimento de estratégias de controle do corpo social urbano que ela obteve prestígio, legitimidade e poder (Foucault, 2004). Nesse período, houve a necessidade de transformação da prática médica, que antes era exercida por leigos empiristas. A medicina moderna surge, então, calcada pelo racionalismo científico pós-renascentista, na busca por um saber e uma verdade pura sobre a doença, independentes do sujeito. Há o início de uma normalização da prática e do saber médico, e, por causa disso, surge a ideia de uma normalização do ensino médico, além de um controle pelo Estado dos programas de ensino e das atribuições desse profissional.

Essa adequação do saber ao discurso científico e do arcabouço instrumental do Estado se fez através da socialização da medicina, devido ao estabelecimento de uma prática coletiva social e urbana, atrelada ao surgimento da ideia da saúde e do bem-estar físico da população, em geral, como um dos objetivos essenciais do poder político. Para isso, em primeiro lugar, a medicina interveio nas relações do estado, depois no espaço urbano e, por último, interveio nos corpos, sobretudo nos de pobres e trabalhadores. Dessa forma, o corpo foi investido socialmente enquanto força de produção e de trabalho

4. Entende-se por rede de cuidados a malha formada pelas opções de cuidados com saúde disponíveis em uma comunidade e o roteiro terapêutico da demanda destes cuidados. 
(Donângelo, 1979). Através de práticas discursivas que delimitavam o espaço dos que detinham o poder-saber e, consequentemente, o poder-dizer sobre o corpo e a saúde, a medicina surgiu como um discurso fundador do corpo saudável atual.

Entretanto, o saber médico oficial, sob a tutela da ciência moderna (positiva, experimental e matematizante) e do Estado, não foi e não é o único saber em relação ao cuidado. Este saber dominante se valeu de diversos mecanismos e estratégias usados contra os saberes ditos "leigos", na construção de sua legitimidade perante a sociedade.

A reza como prática de cura é um fenômeno religioso que resistiu a todas as épocas do processo histórico brasileiro, desde o período colonial aos nossos dias. Essa concepção mágica de cura continua fazendo parte da cultura popular, principalmente de comunidades rurais e tradicionais, uma vez que fé, oração e cura são bases características que dão sustentação ao modo de vida, no âmbito de uma população precariamente assistida pelas ações do Estado (Medeiros, 2005).

Os rezadores se destacam na cura de certas doenças culturalmente delimitadas, tais como, espinhela caída, mau olhado, ventre-virado, ou, então, cobreiro, picada de cobra e de aranha, feridas e doenças infantis, como coqueluche, além de se dizerem capazes de curar uma infinidade de males, sendo a capacidade da cura ligada à questão da fé. ${ }^{5}$ Geralmente, dividem-se as doenças em duas categorias, doenças da alma e doenças do corpo. Por vezes, mesclam suas práticas terapêuticas com outras, como simpatias e chás de ervas (Medeiros, 2005). A prática da reza exige fundamentalmente uma oração, evocada por um rezador ou uma rezadeira, um enfermo com determinada morbidade e a fé entre os dois em relação à cura.

5. Doenças Culturalmente Delimitadas são síndromes que possuem uma relação estreita com o modo de cada cultura lidar com seu adoecimento, dando um caráter territorial a uma doenças, como, por exemplo, o mau olhado que é limitado aos povos de origem ibérica. Outro exemplo é a Espinhela Caída, que só é encontrada em algumas regiões do nordeste brasileiro, se caracterizando como dores no peito, associada a dificuldade de respirar, causada por trabalho pesado, só curado por reza. 
A fé é a parte subjetiva da reza, atrelada ao pensamento dos sujeitos e responsável pela sua eficácia. Mas o sentimento da fé está junto a uma base material, que talvez seja tão importante quanto ele. A palavra constitui esta base e é, em sua materialidade, na forma da oração, que se encontra o poder terapêutico. A palavra é a matéria da fé, o que transforma a reza num fenômeno essencialmente comunicativo, em cujo espaço de interlocução o rezador declama a oração capaz de curar. E é no refinamento desta construção, a oração, que está o seu poder. Na reza, a palavra não é dita simplesmente, ela é proferida para, em nome do mundo divino, interceder sobre o corpo e a doença, trazendo a cura: o ato de fala é ato de fé e cura. A reza é, desta forma, não apenas um ato terapêutico, mas um espaço de pregação da palavra, para que o doente reafirme a sua "profissão de fé”, se arrependendo de seus pecados e reclamando a misericórdia divina.

\section{Os Médicos do estudo}

Os dois médicos entrevistados têm entre quarenta e cinco e cinquenta e cinco anos de idade, e entre vinte e trinta anos de profissão, são do sexo masculino. Ambos nasceram na cidade onde trabalham e se formaram médicos na capital, Recife. Por terem origem nas classes médias baixas e por terem ascendido socialmente através da profissão médica, eles assumem uma posição intermediária entre classes, dominando vários códigos culturais. Apesar de toda a transformação, esses atores sociais preservaram, em certa medida, muitos valores do grupo de origem, se constituindo num mosaico cultural, mas sempre tendendo a optar pelo grupo dominante, num ato de manutenção da posição conquistada.

A sua condição de domínio dos códigos culturais dos grupos populares traria grande vantagem para sua prática em relação aos colegas de profissão, oriundos dos grupos de alto poder aquisitivo. Sua inserção na comunidade em busca da clientela seria fácil, pois haveria a possibilidade de um diálogo mais equilibrado com o paciente, onde 
ele próprio adaptaria de forma habilidosa o seu discurso técnico às condições existenciais de seu cliente.

A proximidade desses médicos com a população mais abastada fez-lhes bons conhecedores das simbologias, dos códigos culturais, das crenças e dos costumes dessa parcela privilegiada. Esse conhecimento faz desses profissionais atores sociais muito importantes para a efetivação dos objetivos da medicina coletiva, que se ocupa primeiramente com esta parte da população, uma vez que a história da medicina coletiva é essencialmente a história da medicina para os pobres (Foucault, 2004a). Assim, este médico, conhecedor do modo de existência das classes populares, na sua condição de intelectual orgânico, se destacaria, tornando-se um ator fundamental na difusão dos modos hegemônicos de cuidado com o corpo, já que sua posição social o coloca naturalmente a favor da ideologia dominante.

\section{Os Médicos e o Outro}

O médico é o sujeito que possui legitimidade por parte do Estado, do capital e da ciência moderna, nas questões que envolvem a saúde e a doença. Ele possui o monopólio legal na produção da verdade sobre a doença, sendo apenas através de seu discurso que a morbidade poderá se revelar. Além disso, a profissão de médico necessariamente implica, pelo menos no imaginário social, uma condição de classe que o coloca como membro de um grupo detentor de alto poder aquisitivo e de prestígio social. Para que cada médico se encaixe dentro deste papel, ele precisa assumir sua condição enquanto membro de um grupo de poder. Mais do que um "curador", será um porta-voz do modo de pensamento dominante. A hegemonia do discurso dos médicos se impõe sobre seus concorrentes. Contudo, a própria prática clínica se transforma, diante da interação com os outros saberes não oficiais, já que estará aplicando sua especialidade num espaço distinto do sistema de valores dominantes. No mundo dos grupos populares, o médico, em muitos casos, não pode impor arbitrariamente a sua medicina, afinal os sujeitos possuem certa autonomia em relação ao seu corpo. 
Além disso, os rezadores e as rezadeiras adquiriram, entre os grupos populares, grande legitimidade, pois fazem parte da comunidade e de seus costumes.

Nesse contexto, os médicos que fazem parte do Programa de Saúde da Família precisam transitar entre a imposição do seu modo de cuidado com o corpo e a tentativa de diálogo para a conquista da confiança da comunidade. ${ }^{6}$ Esse é um jogo cujo único objetivo é tornar hegemônico o controle da medicina sobre o modo de cuidado com o corpo (Montero, 1985). Uma reação comum dos médicos em relação às práticas de cura tradicionais é a tentativa de desqualificação, associando-as com o estado de "ignorância" vivida pela população pobre, devido ao pouco acesso à educação escolar de qualidade.

Tem umas doenças, por exemplo, erisipela, cobreiro... aí sempre pede pro rezador. Porque essas doenças têm um ciclo. Entendeu? A gente pega cobreiro. Não tem remédio. É um sintomático. Aí pega um paciente com cobreiro. No começo são oito dias de inquietação. De dor, de furada, de espinhada. Aí passa o sintomático pra aliviar aquelas dores. Com oito dias ele perde a paciência porque não ficou bom. Aí vai pro benzedor. Aí o cara lá reza. Aí completa o ciclo da doença. Quem curou foi o benzedor. Isso tudo é folclore. (Homem, médico, 55 anos)

No relato acima, a cura pela reza é associada ao fim dos ciclos de doenças agudas. A cura, nestes casos, seria inevitável, diante do bom prognóstico de grande parte dessas doenças, sendo o fenômeno da cura uma simples coincidência com o fim do ciclo da doença. Segundo o sujeito médico, a incapacidade de a medicina atuar de maneira eficaz em algumas dessas doenças, restando apenas o tratamento dos sintomas, faz com que o paciente desacredite na ação da terapia. Dessa forma, o rezador ou a rezadeira se beneficiaria

6. O Programa de Saúde da Família (PSF) foi criado a partir do Sistema Único de Saúde como alternativa ao modelo tradicional que priorizava o hospital como centro de cuidado. Neste modelo, o médico sai de seu local de poder (o hospital) e entra no cotidiano da comunidade, através de reuniões com a população, visitas domiciliares e atividades educativas, abrindo espaço para um contato maior com as formas tradicionais de cuidado que as comunidades dispõem. 
do sistema, recebendo o mérito pela cura do enfermo, e conquistando o paciente da medicina.

A postura do médico justifica-se, pois, acreditando nessas crenças, além de beneficiar seu concorrente, o médico iria contrariar o mundo do qual faz parte. Toda prática do médico é teoricamente embasada na ciência positivista e não admite ambiguidades ou relativismos. Concordar com uma eficácia de uma prática que está fora do sistema explicativo da ciência moderna é negar o que legitima a medicina (cf. Foucault, 2004), o seu sistema hegemônico, abrindo a possibilidade de existência de diversas verdades sobre o mundo. Contudo, a origem mais popular dos médicos entrevistados os coloca mais perto das práticas populares de cuidado e do próprio sistema de valores da comunidade. $\mathrm{O}$ médico pode não rejeitar completamente o mundo do outro, assimilando parte das crenças e entrando em contradição com suas posições em relação à reza. Embora a medicina e a reza estejam separadas pelo abismo que o racionalismo científico lhes impôs, o rezador e a rezadeira não são figuras tão estranhas aos médicos que cresceram na zona rural. A proximidade com a reza no seu cotidiano poderia proporcionar a experiência empírica de sua eficácia, convencendo o médico da veracidade da terapia da reza, pelo menos, em parte. No depoimento abaixo, o mesmo médico que antes desqualificou a reza, afirma sua eficácia em relação a uma patologia:

Mas tem coisa interessante na medicina tradicional. Pra verruga não tem coisa melhor que rezar. Pode acreditar que funciona. Eu tenho muita experiência e vi que funciona mesmo. Eu não sei se prepara praquela verruga cair e quando o cara tá rezando há uma descarga de alguma substância do organismo que vai atuar na verruga e ela cai. Cai e eu tenho certeza absoluta. O cara queima, usa leite de pau e não cai. E é só rezar que $80 \%$ das verrugas cai. (Homem, médico, 55 anos)

O médico atesta firmemente, a partir de sua experiência empírica, a eficácia da reza no tratamento de verrugas. Chega até mesmo a dar a percentagem do índice de cura, numa tentativa de mostrar mais consistência à sua verificação. Ele tenta, inclusive, adequar sua fala ao discurso científico, argumentando no sentido de legitimar seu 
achado. Certas características do discurso da medicina presentes no depoimento do médico podem se interpretadas à luz da hegemonia do discurso médico em situações que exigem do profissional um vocabulário que o identifique. Para Fairclough (2001: 265), técnicas transcontextuais, como entrevistas, assumem grande importância na sociedade atual, tanto que "as tecnologias do discurso estabelecem uma ligação íntima entre linguagem e discurso e poder”.

É interessante notar que, embora o médico afirme a eficácia da reza nos casos de verrugas, no momento de formular hipóteses sobre o fenômeno, elabora um modelo explicativo baseado em construções biomédicas. Não é a fé ou as forças divinas que curaram oitenta por cento dos casos de verrugas, mas alguma substância endógena, liberada no momento da reza, que possui ação sobre a enfermidade. Pra verruga eu recomendo. Cai com a crença popular. Acho eu que uma descarga de adrenalina ou uma vitamina que agente não conhece ainda. Com simpatia cai. Eu tenho a experiência de mais de cem casos. $\mathrm{O}$ cara veio de um dermatologista de Recife, veio pra mim e eu disse vai benzer ali (risos). Principalmente criança. (Homem, médico, 55 anos)

O médico se arrisca até em citar a natureza da possível substância responsável pela ação terapêutica. Embora se remeta à crença popular como importante dentro do processo, é justamente a ação psicológica da fé, o possível fator de liberação da substância. Nesse modelo explicativo, a reza só é aceita em parte, pois, mesmo sendo sua ação verificável empiricamente, sua essência se perde ao ser adaptada aos modelos científicos. Toda tradição inerente ao seu universo de crenças e ao próprio modelo explicativo do rezador ou da rezadeira não são levados em consideração pelo médico, mesmo tendo afirmado firmemente nesse caso sua crença.

Diante da legitimidade que o rezador e a rezadeira possuem na comunidade, torna-se complicado opor-se incisivamente a esses agentes, pois isso ameaçaria a confiança entre médico e população. Dessa forma, há necessidade de se fazer uso de estratégias mais eficazes de inserção dentro da comunidade, como, por exemplo, usar o próprio rezador ou a rezadeira como aliados nesse processo. A 
importância que a reza assume dentro do repertório terapêutico das comunidades rurais nordestinas, coloca o especialista da reza como um aliado estratégico para efetivação dos objetivos dos serviços de saúde oficial. Assim, o médico pode tentar conquistar a amizade e confiança desse ator social, fazendo o rezador ou a rezadeira se sentir como colega na prática da cura bem como pode não admitir, para o paciente, sua descrença na prática da reza, para cumprir com seus objetivos.

Mas nossa relação é boa. Embora dá um trabalho arretado, que me atrapalha um bocado. Tem um rezador aqui que rezava no povo, mas quando era preciso me chamava. Aí quando ele ia me pagar eu dizia: - Já visse colega pagar outro? (risos). Eu dizia pra ele e ele ficava satisfeito. Ele me ajudava pra convencer os pacientes a tomar os remédio. Teve um cabra que se engasgou com um osso. E foi pro médico em Princesa [Princesa Isabel, na Paraíba] e o médico não conseguiu tirar o osso. Aí disseram: "Manda Fulano rezar". Aí Fulano chegou, olhou o paciente, rezou, mandou comer umas farinha, umas banana. Aí o osso desceu. Aí o menino saiu satisfeito e Fulano disse: "Amanhã na saída, se enganchar, me chame". (risos). Mas eu me dou muito bem. Eu sempre digo "reza não faz mal, mas não serve". Mas também não vamos dizer pra não perder o paciente. (Homem, médico, 55 anos)

Para os médicos, em boa parte das situações, a reza representa um incômodo para a efetivação dos seus esquemas terapêticos, já que grande parte dos enfermos preferiria a reza como opção de cuidado. Por causa disso, ou os pacientes deixariam de ir ao médico ou abandonariam o tratamento alopático. Por um lado, o médico precisa da reza como aliada para sua inserção dentro da comunidade, por outro, precisa a todo custo impor seu modo de cuidado. Esse fato se nota perfeitamente em:

[...] como o exemplo do paciente que foi pro rezador. E ele voltou, ele com artrite, outro médico passou um remédio e o rezador mandou ele não tomar o remédio, mandou passar 30 dias sem tomar um comprimido. E ele com uma média de 15 dias, ele tava que não podia nem andar. Me pediram que eu fosse lá. Aí eu disse: vamos fazer o seguinte, você não acredita na reza, você não confia? Então continue 
acreditando, pode acreditar, eu também acredito, é muito importante, mas eu vou aplicar em você um voltarem, um dipirona, em injeção. Com três dias o cara tava andando. (Homem, médico, 48 anos)

Podemos observar nessa última narrativa que, para o médico, embora a opção pelo rezador tenha sido responsável pela piora do paciente, impedindo-o de seguir o tratamento adequado, foi necessário, para a continuidade do tratamento médico, dizer que acreditava na importância da reza, convencendo o enfermo a continuar o tratamento alopático. Em outras palavras, o médico não se revelou contrário ao conjunto de crenças da comunidade, com medo de afastar-se ainda mais de seu cliente.

Segundo os depoimentos dos médicos, poderia haver até vantagens no uso da reza em regime complementar à medicina oficial, pois, se por um lado não há a crença em sua efetividade, eles percebem-na como importante no tratamento, pois o ritual do ato de reza traria confiança na cura e calma ao paciente, auxiliando o médico no processo terapêutico. Pode-se observar esta posição na narrativa deste médico:

Não tem problema não, a reza se não fizer bem, mal não faz. É tudo um fator psicológico. A rezadeira faz aquele negócio bem bonito, né? E a pessoa fica impressionada. Você vai ficar bom, porque Deus quer que você fique bom. Pode ficar tranquilo que você vai ficar joia. Aí com aquilo na cabeça a pessoa tá doente, mas fica tranquilo. (Homem, médico, 48 anos)

Já que a reza foi associada, nas entrevistas com os médicos, à "ignorância” que resiste entre as comunidades rurais brasileiras, uma melhora no nível educacional da população seria responsável pelo processo de desaparecimento dessa prática. A própria informação em saúde levada pelas Equipes de Saúde da Família ou a televisão ajudariam a população a se libertar dessas formas "atrasadas" de cuidado com o corpo.

Mas hoje o povo tá mais educado. A gente educa, a televisão educa. É só o menino tá doente que leva pro médico, dá soro. Mas antigamente se perdeu muita criança por conta da reza, que deixava de 
tratar. Mas eu digo que a mortalidade aqui é muito baixa. Você não vê mais enterro de anjo. Isso devido ao esclarecimento do povo. E também com esse sistema de PSF que vai educando o povo. Menino, cuidado na mosca, lava mamadeira, lava chupeta. (Homem, médico, 55 anos)

\section{Os Rezadores e o Outro}

Todos os rezadores e as rezadeiras entrevistados são de origem popular, mantendo-se nessa condição durante toda sua vida. Devido a isso, além de serem marginalizados em sua prática pela medicina oficial, são também marginais em sua condição de grupo não hegemônico, desprovidos de condições adequadas de vida. São possuidores de um saber não legitimado pelas instituições ligadas ao Estado, tomando uma posição à parte dos saberes oficiais de cuidado. Por conta de possuírem um saber tradicional, de raízes fortemente ibéricas, afrobrasileiras e indígenas, e por estarem à margem da educação oficial, foram resistentes aos processos de aculturação.

A reza não seria simplesmente uma terapia, mas $a$ forma de encontro com o sagrado, capaz de curar o corpo e acolher a alma dos indivíduos, cheia de sofrimentos. Justifica-se assim a legitimação de uma prática, tão fortemente ligada à religiosidade, junto aos grupos populares, já que se crê na influência radical do mundo divino em todas as instâncias das relações entre os seres humanos e o mundo que os rodeia. Essas são as condições objetivas que precedem os especialistas da reza em suas relações com os diversos atores que compõem o corpo da sociedade. Aqui, este outro, nesse caso, o conjunto dos médicos, não será tão facilmente assimilável. O médico sempre fará parte de outro nível de compartilhamento da realidade, mostrando-se geralmente como um estranho à comunidade, impondo seu estilo de vida, costumes, crenças e visão de mundo. Nesse tipo de encontro com o outro, há grande espaço para a geração de conflito e embates de visões de mundo, sendo necessária a criação de estratégias e formas de convivência que permitam a sobrevivência cultural dos agentes da reza. 
No jogo de forças travado, o rezador e a rezadeira fazem parte do lado mais desprotegido, já que não possuem a hegemonia que lhes garanta o poder junto aos aparelhos ideológicos dos grupos dominantes. Para sobreviver no campo de lutas, a reza precisa ser validada por mecanismos bem mais refinados para se perpetuar enquanto prática e modo de ver o mundo. Um dos mecanismos seria eliminação ou atenuação do confronto direto, do contato corpo a corpo, driblando as situações de conflito e discordâncias, se isolando da ação do outro. O médico só seria procurado quando acabasse todo repertório terapêutico existente, dando preferência ao tratamento alternativo em casa. Dessa forma, diminuir-se-iam situações de imposição de formas de cuidado vindas dos médicos. É o caso dessa rezadeira:

Eu levo meu pessoal pro médico porque realmente tem causo que só se resolve no médico mesmo. Só levo quando não tem outro jeito. Mas a maioria das coisa mesmo, eu não levo. Médico gosta de mandar demais. (Mulher, rezadeira, dona de casa, 46 anos).

Ao constatar a necessidade de um tratamento médico, nota-se o conhecimento nosológico da doença por parte da informante. Uma forma de se proteger contra a ação da medicina oficial é diferenciar as doenças de acordo com a terapia mais apropriada: a clínica ou a reza. Haveria doenças mais sensíveis à ação do rezador ou da rezadeira, como também outras mais apropriadas para serem tratadas pelo médico. Essa é uma forma de escape da perseguição dos mecanismos legais que protegem a medicina oficial como também é uma forma de se legitimarem dentro da comunidade, já que trabalham com um sistema de cura e um repertório de males distintos da medicina oficial. Assim, protegem seu saber.

Doença que médico resolve eu nem ouso em ir lá. Se for coisa do espírito ou mais forte que remédio, médico cura? Ele não tira. E nem o remédio tira. Ou reza ou mesa espírita. Mas essas coisa de mesa já não é comigo, pois destas coisas eu nem chego perto." (Homem, rezador, agricultor, 82 anos) 
O médico parece ser, de acordo com as narrativas do agente da cura espiritual, incapaz de entender as morbidades específicas da reza, já que não faz parte de seu sistema de compreensão da doença. Conforme o rezador, as doenças consideradas de causa sobrenatural só poderiam ser curadas por um rezador ou uma rezadeira, que intervêm sobre o mal através do sagrado. Talvez seja essa uma forma de colocar sua prática à parte da medicina oficial, amenizando a concorrência e o conflito entre ambos.

Assim, as pessoa sente coisas diferente. E vai pro médico. Aí chega lá, aí receita e diz: você não tem doença. Isso é uma ilusão sua. Faz exame e dá tudo normal, tá tudo bem. E aquilo matando as pessoa. Só vive doente, não come, só vive assustado, não sei o quê. Chega aqui, aí eu digo: isso é coisa de fora. Vamos desmanchar. Aí eu desmancho. (Mulher, rezadeira, agricultora, 66 anos)

A fé, como fator regente da vida e da própria prática da reza para o rezador/ a rezadeira, estabelecia o mérito da graça desejada. Esse é o principal argumento que faz a reza se sobrepor à medicina, já que a própria prática médica estaria sob determinação dos poderes divinos. Assim a prática dos médicos dependeria da vontade de um Deus onipresente e onipotente; e sem essa permissão sacra a medicina perderia sua eficácia. No relato que se segue, o rezador defende a subordinação dos médicos a Deus:

Bom se Deus quiser dá. Não é eu que quero. Ele disse que a reza não dá pra todo incômodo. Terá incômodo que remédio também não dará. Mas pra Deus nada é impossível. Por isso eu não garanto por vida de ninguém. Nem que aquilo serve ou que não serve. Eu só confio em Deus. O povo chega aqui e eu diga minha gente vocês têm essa fé tão grande em mim. Não acredite em mim não. Acreditem que existe Deus. Que é se Deus quiser. (Homem, rezador, agricultor, 82 anos)

Nesse contexto, a reza está num plano acima da medicina, por conta da proximidade das forças do mundo divino. Forças estas, para os rezadores/as rezadeiras, que desafiam a razão e a vontade humana, se sobrepujando sobre as coisas terrenas. É a fé surgindo como refúgio 
da esperança do fim dos sofrimentos da vida, vencendo os desmandos criados pelos homens. É na esperança de dias melhores que mora a subversão dos grupos explorados, depositando no sagrado a força para continuar a lutar pela vida. "Nada é impossível quando Deus quer", máxima que ultrapassa distâncias e realiza o impossível, até mesmo para a medicina. São esses argumentos comuns entre os agentes da reza, como nesse trecho: "É a fé em Deus. Eu mermo tenho rezado pra algumas pessoas que o médico tá com ele, mas eles dizem pra mandar rezar neles pra ajudar". (Homem, rezador, agricultor, 82 anos). Da mesma forma o fragmento: "Mas não fiquei bom ainda não. Quase que fui desenganado de novo. Me deu umas crise medonha, mas vou ficar curado. Quem cura é Jesus" (Homem, rezador, aposentado, 63 anos).

A rezadeira ou o rezador não pode cobrar pelos seus serviços enquanto agente terapêutico, já que está a serviço do sagrado, porque o comércio da reza é contra os princípios divinos, nos quais a doação ao próximo, como forma de caridade, seria uma das matrizes de conduta. Não se pode vender um dom dado por Deus. Dessa forma, um médico cobrar pelo seu serviço é perfeitamente aceitável, já que a medicina faz parte da dimensão terrena, sob a tutela dos valores humanos. O médico não nasce médico, tendo que enfrentar o mundo dos homens para conquistar sua posição, justificando cobrar pelo seu esforço. É o que se nota na narrativa deste rezador:

O médico tem razão de cobrar porque gastou, pra se formar e tiveram grande despesa. Eu não tenho despesa nenhuma. Eu aprendi porque Deus me consentiu e ele não me cobrou e nem eu paguei. (Homem, rezador, agricultor, 82 anos)

Contudo, a falta de uma atitude mais caridosa por parte dos médicos não traria uma boa imagem para ele, já que, segundo alguns rezadores, o lucro seria o objetivo mais importante na medicina. Nessa perspectiva, uma lógica perversa surge, se o médico lucra com a doença; a cura, logo, não é vantajosa. Para o agente da reza, o interesse financeiro do médico se superpõe ao sofrimento do outro, condição sempre implícita em cada atendimento ou visita domiciliar. No relato abaixo, a rezadeira diferencia a efetividade da ação entre os médicos 
que trabalham com caridade e os que trabalham apenas visando ao lucro:

Porque eu acho que os médicos são mais pelo dinheiro. Não é por amor. Às vezes, aqueles que trabalham por amor, acertam. Mas aqueles que trabalham pelo dinheiro nunca acertam. Onde que a pessoa que vive de doença vai querer ver o povo sadio. (Mulher, rezadeira, aposentada, 90 anos)

Embora haja na relação entre esses atores uma concorrência implícita, percebe-se entre os rezadores e as rezadeiras uma disponibilidade para uma ação conjunta, bem maior que no caso dos médicos. Apesar de alguns ataques à prática dos médicos por parte dos rezadores e das rezadeiras e de não verem a medicina como a alternativa mais eficaz, de maneira geral, não há por parte desses um discurso que deslegitime o seu concorrente. É o caso deste rezador que enfatiza seu prestígio com a medicina oficial, pois médicos encaminham pacientes para serem rezados por ele:

Todos não. Ali tem mesmo um que levaram um doente pra ele e disseram que mandaram rezar, aí ele disse: Que reza o quê? Eu lá acredito em reza! Reza vale nada. Mas dotô [cita nome do médico] acredita. Ele mesmo manda paciente pra eu rezar. Agora mesmo eu tô rezando numa senhora ali numa grota que eu só vou pra lá por que eu tenho que ir. Que é longe. E tá indo eu e o dotô cuidar dela e ela tá ficando boa. (Homem, rezador, agricultor, 82 anos)

A atitude dos médicos, ao se aproximarem da reza, gera um tipo de consórcio, no qual ambos os atores dividem a responsabilidade pelo paciente. Assim, pode o rezador ou a rezadeira retribuir a confiança depositada pelo médico.

Uma parte médico e otra reza. Uns corre logo pro médico, mas nem sempre dá certo. Aí chega aqui dá certo. Otros chega aqui, eu vejo que não é pra mim, aí eu mando pro médico. A gente sabe que muitos problema é pro médico. Se for pra mim resolvo, se não mando pro médico. A gente tem que entender uns os otos. Aqui na minha casa anda padre, madre, todo tipo de gente. A gente tem que compreender. (Mulher, rezadeira, agricultora, 66 anos) 
Nessa associação, o médico que se mostra crente na reza, ou que compartilha modos semelhantes de encarar a realidade, possui grande prestígio entre esses atores sociais.

Acredita. Nem todos. Eu dou ponto ao médico que acredita. Acredito em médico que acredita em rezadeira. Que acredita na oração. Assim eles não dizia: Tá entregue nas mãos de Deus. Quer dizer que eles não têm força nenhuma. Eu só acredito em médico no que eu não posso fazer; arrancar dente e ter menino. (Mulher, aposentada, rezadeira, 90 anos)

A maior abertura ao diálogo pode ser interpretada como uma forma de aceitação da medicina dentro de determinados limites, diante de seu poder e da impossibilidade de confronto direto. Já que é inviável um ataque a um concorrente tão poderoso, é mais estratégico criar formas de consenso, se associando com outro. Com isso, pode-se amenizar a perseguição por parte da medicina, além de esse contato trazer um maior prestígio e legitimidade social, associando a figura do rezador à do médico, ator social de grande poder.

Outra maneira de se interpretar essa relação é através do conceito de hegemonia. A rezadeira ou o rezador não fazem parte dos grupos hegemônicos nem de seus conjuntos de valores. Sua condição de classe, de origem na agricultura familiar coloca-os mais próximo aos grupos populares. No entanto, não necessariamente por fazer parte do grupo não hegemônico (como se pode pensar), o rezador ou a rezadeira são agentes contra-hegemônicos (cf. Gruppi, 2000). Isso porque, ao contrário dos médicos, a reza não pretende, através de seus representantes, chegar ao poder, obter o monopólio em relação à cura. $\mathrm{O}$ que está em jogo na relação com a medicina oficial é o direito de manter sua tradição, seu modo de vida que faz com que ele seja o que é. Não pretendendo o poder, não é de se admirar que o/a rezador/rezadeira possua uma maior abertura para o diálogo, aceitando de forma mais pacífica o contato com outro. O outro, neste caso, mais do que como concorrente, só representa uma ameaça quando faz uso de seu poder para minar o modo tradicional de cuidado que a reza constitui. 


\section{Considerações finais}

Os representantes da reza e da medicina se (re) significam como sujeitos-cuidadores, construindo a partir daquilo que representam e daquilo que o outro "é", qual o seu papel e a sua função nos cuidados. Cada um desses representantes tem no outro aquilo que não é, mesmo quando recorre aos cuidados desse. Assim, os médicos entrevistados, mesmo tendo nascido no meio rural, não mais ratificam a tradição da reza, ao contrário, utilizam-se dos rezadores e das rezadeiras para reafirmar a sua rede de cuidados, aproveitando-se da tradição da reza na comunidade, para introduzir a cultura da medicina. Por sua vez, reconhecendo-se como representante da reza e do divino, rezadores e rezadeiras, já tendo seus meios de cuidados aceitos na comunidade, não precisam utilizar-se do discurso médico para inserirem sua rede de cuidados, embora reconheçam nesse novo sujeito-cuidador um modo de valorização da sua função.

O jogo estabelecido entre o eu e o outro na constituição da identidade de cada um desses representantes demonstra uma abertura maior de diálogo por parte dos representantes da reza, uma vez que esses não chegam a duvidar que os médicos tenham a sua função na cura. Diferentemente, os médicos, para estabelecerem suas práticas de cuidado na comunidade, embora necessitem "admitir em público" a crença na cura pela palavra divina, não aceitam o outro como interlocutor do discurso do cuidado. A construção da identidade encontra, no discurso dos sujeitos, formas de (re)significação dos papéis e valores assumidos pelas pessoas na sociedade. Dizer que somos também feitos de palavra é reconhecer que a linguagem é performativa e nos (re)cria à medida que é (re)criada. A identidade é, assim, um construto mutável segundo práticas sociais e discursivas que moldam pessoas e objetos.

Enviado em: dezembro de 2010 Aceito em: março de 2011 sandrahdmelo@yahoo.com.br jarbasnunes@yahoo.com.br 


\section{Referências bibliográficas}

ALTHUSSER, L. Ideologia e aparelhos ideológicos de Estado. In: S. Zizek (org). O mapa da ideologia. Rio de Janeiro: Contraponto, 1996, pp. 105-142. AUSTIN, J. L. Performativo/constativo. In: P. Ottoni. Visão performativa da linguagem.

Campinas: Ed. da UNICAMP, 1998, pp. 109- 144.

BENHABIB, S. A crítica da razão instrumental. In: S. Zizek (org). O mapa da ideologia. Rio de Janeiro: Contraponto. 1996, pp. 71-96.

BOLTANSKI, L. As classes sociais e o corpo. São Paulo: Paz e Terra, 2004.

BOURDIEU, P. Pierre Bourdieu: sociologia. In: R. Ortiz (org.), São Paulo: Ática, 1983.

BUTLER, J. Excitable speech. A politics of the performative. New York, London: Routledge 1997.

DONNANGELO, M. C. F. Saúde e sociedade. $2^{\circ}$ ed. São Paulo: Livraria Duas Cidades, 1979.

FAIRCLOUGH, N. Discurso e mudança social. Brasília: Ed. UnB, 2001.

FELMAN, S. The scandal of the speaking body. Stanford: Stanford University Press, 2003[1983].

FOUCAULT, M. Microfísica do poder . $19^{\circ}$ ed. Rio de Janeiro: Ed GRAAL, 2004a.

FOUCAULT, M. $O$ nascimento da clínica. $6^{\circ}$ edição. Rio de Janeiro: Ed Forense Universitária, 2004b.

GRUPPI, L. O conceito de hegemonia em Gramsci. Rio de Janeiro: Graal, (2000[1978]).

HORKHEIMER, M. Teoria tradicional e teoria crítica. In: Textos Escolhidos. Coleção Os Pensadores. São Paulo: Ed. Victor Civita, 1975, pp. 125-161.

MEDEIROS, M. R. Rezar, curar: um caso de persistência cultural no Seridó. MNEME Revista de humanidades, UFRN. Rio Grande do Norte, v.3, $\mathrm{n}^{\circ}$ 5, abr./ma. 2002. Retirado de www.seol.com.br/mneme. Acesso em nov. 2002. MONTERO, P. Da doença à desordem: a magia na umbanda. $1^{\circ} \mathrm{Ed}$. Rio de Janeiro: Edições Graal, 1985 
PLATÃO. Crátilo. Lisboa: Instituto Piaget, 2002

RAJAGOPALAN, K. A construção de identidades e a política de representação. In: L.M.Ferreira \& E. G. D. Orrico (org.). Linguagem, identidade e memória social. Rio de Janeiro: DP\&A, 2002, pp. 77-88.

RYLE, G. Linguagem ordinária. Os Pensadores. Abril Cultural. São Paulo: Victor Civita, 1975, pp. 43-58. 